\title{
Novel, double-lumen removable stent to treat caustic esophageal stenosis
}

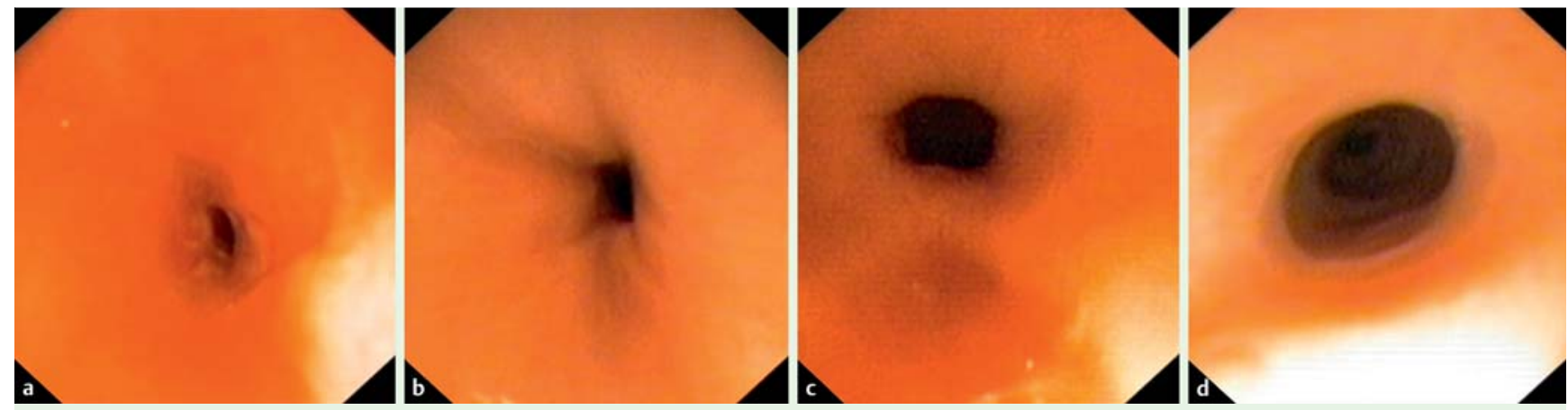

Fig. 1 Endoscopy images of the esophagus (Olympus GIF-XP160). a 3 weeks after chemical injury (Dec 2012), critical esophageal lumen stenosis was observed. b Before tube stent placement (Apr 2013), the esophageal stenosis prevented endoscope passage. c After tube stent removal (Sep 2013), esophageal stenosis was still visible but did not obstruct the passage of the endoscope. $\mathbf{d} 6$ months after tube stent removal (Mar 2014), rigidity and cicatrization of the esophageal wall was observed with no difficulty in passing the endoscope.
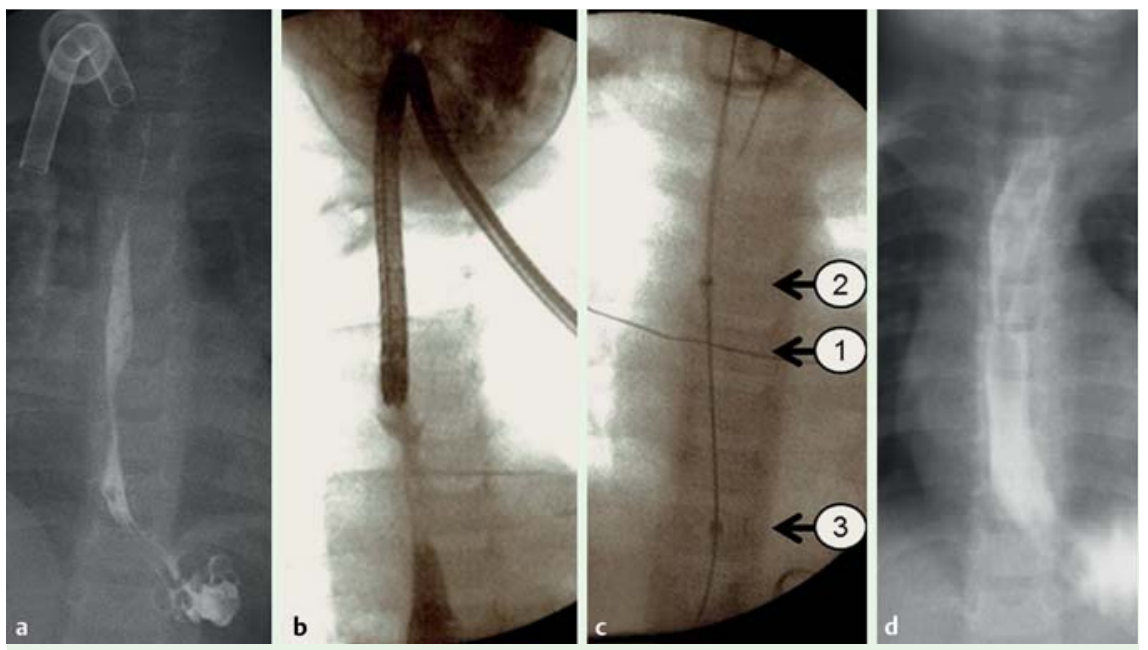

Fig. 2 Radiographs of the esophagus. a 3 weeks after chemical injury (Dec 2012), stenosis and an irregular esophageal wall were observed. b Endoscopic esophageal Savary-Gillard 7-mm dilation 5 weeks after chemical injury (Dec 2012); the esophageal stricture length was two vertebrae. c Tube stent placement (Apr 2013): 1 = marker indicating the upper stenosis border; 2 =marker indicating the upper margin of the main part of the tube stent; 3 =marker indicating the lower margin of the main part of the tube stent. $\mathbf{d} 6$ months after tube stent removal (Mar 2014), the esophagus without stenosis.

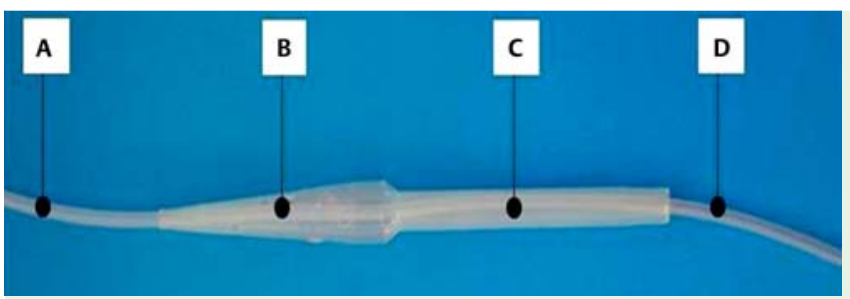

Fig.3 Polyamide tube stent for long-term placement in patients with recurrent esophageal stenosis. $\mathrm{A}=$ Proximal part of the 8-Fr nasogastric tube. $\mathrm{B}=$ Conical perforated proximal part of the tube stent. This part is located above the upper margin of the stenosis. The perforations allow for easy passage of fluids through the main part of the tube stent into the lower esophagus and stomach. $C=$ The main part of the tube stent, which is inserted within the stenotic area. $\mathrm{D}=$ The distal part of the 8-Fr nasogastric tube. The tube stent was registered at Polish Patent office (P.399031). Tube stent manufacturing technology and prototypes (length $7 \mathrm{~cm}$ and diameter 7 or $9 \mathrm{~mm}$ ) were developed at Balton sp.z oo (Warsaw, Poland).
Recurrent esophageal stenosis following caustic injury may be difficult to treat. A tube stent developed at our institution [1] can be used as an alternative to repetitive endoscopic esophageal stricture dilation. The case of a boy with severe larynx and esophageal caustic injury at the age of 2 years is reported here.

Endoscopy ( $\bullet$ Fig. $\mathbf{1}$ a) and radiography $(\bullet$ Fig. 2a) performed 3 weeks after the accident showed esophageal stenosis. Within the subsequent 4 months, the patient underwent six endoscopic esophageal Savary-Gillard bougienage dilation procedures (up to 7-9 mm) under radiographic control ( $\bullet$ Fig. 2 b) without longterm restoration of the esophageal lumen. At 5 months, esophageal stenosis was still present ( $\bullet$ Fig. $\mathbf{1}$ b) and the patient tolerated only a liquid diet. Thus, the patient underwent implantation of a double-lumen, variable-diameter, perforated nasogastric tube stent ( $\bullet$ Fig.3) under radiographic control ( $\bullet$ Fig. $2 \mathrm{c}$ ).

Tolerability of the tube was satisfactory. The patient accepted the proximal end of the tube extending from the nose, tolerated a semiliquid diet, and gained weight without the need for additional gastric tube feeding ( $\bullet$ Fig. 4 ).

The tube was removed after 5 months, and endoscopy showed restoration of the esophageal lumen ( $\bullet$ Fig. 1 c). At 6 months after tube stent removal, the patient tolerated a normal diet and gained weight $(\bullet$ Fig.4). Radiography showed no esophageal stenosis ( $\boldsymbol{~ F i g . 2 d ) , ~ a n d ~ e n d o s c o p y ~}$ revealed rigidity and cicatrization of the 


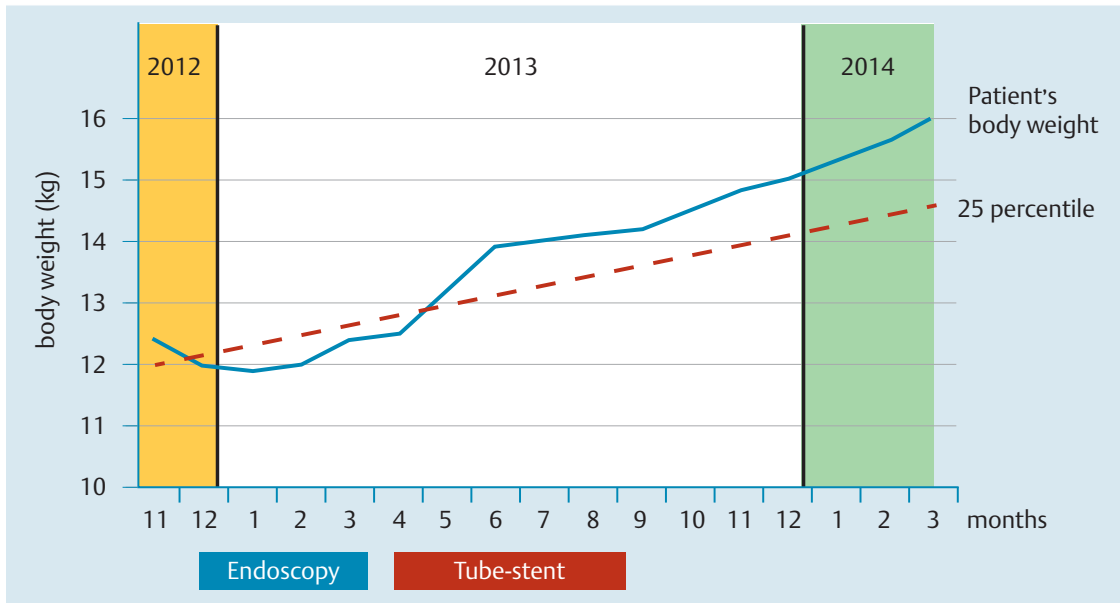

Fig. 4 Changes in the patient's body weight during phases of therapy: endoscopic dilation, tube stent therapy, and post-treatment follow-up.

esophageal wall with no difficulty in passing the endoscope ( $\bullet$ Fig. $1 \mathrm{~d}$ ).

The presented case shows that providing long-term artificial support to prevent narrowing of the esophageal lumen can restore the function of the esophagus and eliminate the need for repeated esophageal dilation. A similar approach has been described in the literature [2-5]. However, to the best of our knowledge, none of the devices used by other authors are commercially available.

Endoscopy_UCTN_Code_TTT_1AO_2AI

\section{Competing interests: None}

Marek Woynarowski ${ }^{1}$ Maciej Dądalski ${ }^{1}$, Violetta Wojno ${ }^{1}$, Mikołaj Teisseyre ${ }^{1}$, Leszek Hurkała ${ }^{2}$, Emil Płowiecki²

${ }^{1}$ Department of Gastroenterology Hepatology and Feeding Disorders, Children's Memorial Health Institute, Warsaw, Poland

${ }^{2}$ Balton sp. z oo. Warsaw, Poland

\section{References}

1 Woynarowski M, Dądalski M, Wojno V et al. Nasogastric tube as protection for recurrent oesophageal stricture: a case report. World J Gastroenterol 2014; 20: 4806-4810

2 Atabek C, Surer I, Demirbag S et al. Increasing tendency in caustic oesophageal burns and long-term polytetrafluorethylene stenting in severe cases: 10 years' experience. J Pediatr Surg 2007; 42: 636-640

3 Bicakci $U$, Tander B, Deveci $G$ et al. Minimally invasive management of children with caustic ingestion: less pain for patients. Pediatr Surg Int 2010; 26: 251 -255

4 Mutaf 0 . Treatment of corrosive oesophageal strictures by long-term stenting. J Pediatr Surg 1996; 31: 681-685

5 Foschia F, De Angelis P, Torroni F et al. Custom dynamic stent for oesophageal strictures in children. J Pediatr Surg 2011; 46: 848-853

\section{Bibliography}

DOI http://dx.doi.org/

10.1055/s-0034-1377373

Endoscopy 2014; 46: E378-E379

(c) Georg Thieme Verlag KG

Stuttgart · New York

ISSN 0013-726X

\section{Corresponding author} Marek Woynarowski, MD, PhD

Department of Gastroenterology Hepatology and Feeding Disorders

Children's Memorial Health Institute

Al. Dzieci Polskich 20

04-730 Warsaw

Poland

Fax: +48-22-8157382

m.woynarowski@czd.pl 